\title{
Is There a Causal Relationship Between Financial Markets in Asia and the US?
}

\author{
Amalendu Bhunia* and Devrim Yaman**
}

\begin{abstract}
This study examines whether there is a causal relationship between selected stock markets in Asia and the US. Based on stock values from a sample of nine Asian stock markets, we find a positive correlation with US stock market prices in most cases, the exception being Vietnam. Our results indicate significant long-run and short-run causality in both directions between the Asian and US stock markets. These findings show that, while both sets of markets are integrated, there are still valuable opportunities for international investors to diversify their portfolios in the US and Asia.
\end{abstract}

Keywords: stock market, short and long term causality, Asia, USA.

JEL classification: F21.

\section{Introduction}

The integration of international capital markets is widely debated in the finance literature. Capital market integration has implications for both policymakers and investors. An important reason for studying this integration concerns the potential gains from international portfolio diversification. The interrelationships among international stock markets have implications for asset allocation as well as risk management. The recent global financial crises and their contagion effects show that co-movements and causal relationships between stock markets need closer analysis.

Asian markets provide valuable opportunities for investors, given that the rise of the middle class in this region has allowed consumption levels to expand, creating numerous pockets of growth. For example, a report by Aberdeen Asset Management, Henderson Global Investors and What Investment (2016) shows that, although economic growth in China has slowed down, its GDP growth rate has remained strong. Moreover,

\footnotetext{
* Professor, Department of Commerce, University of Kalyani, West Bengal, India.

** Associate Dean and Robert J. Bobb Professor of Finance, Haworth College of Business, Western Michigan University, Kalamazoo, MI, USA.
} 
the country is characterized by robust domestic consumption, low valuations and reforms in the state-owned enterprise sector. Japan, which has undergone economic reforms to enhance its global competitiveness, has an aging population with large disposable incomes, thereby opening up opportunities for investment in nursing homes, medical equipment and holiday resorts. India continues to attract investors, given the optimism surrounding its economic prospects and stock valuations. Part of this relates to declining commodity and oil prices as the country is a net importer of both. Finally, Korea has experienced positive change with the growing involvement of minority shareholders, who are now taking on a proactive role in their companies and even voting against the board.

The US has long provided foreign investors with attractive opportunities. Not only do they benefit from the country's efficient, liquid and highly developed markets and its strong corporate institutions, but they can also diversify risk when investing in the US, particularly if their own financial markets have a low correlation with the US market (Forbes, 2008).

Deregulation and the liberalization of capital markets, combined with technological advances, have allowed Asian and US markets to become more integrated over time. Numerous financial events point to this increasing correlation. For example, in the summer of 1997, when a large portion of East Asian currencies fell by as much as 38 percent, leading to a sharp drop in the stock market indices of these countries, the Dow Jones Industrial Average (DIJA) plunged by 7.2 percent on 27 October. In early 2016, when Japan cut its short-term interest rates, the US market responded with a drop of 11.5 percent between 1 January and 11 February.

This study investigates the causal relationship between the US financial market and nine Asian markets, including India, China, Japan, the Republic of Korea, Vietnam, Indonesia, Malaysia, the Philippines and Singapore. We test the correlation between these stock markets and the US market to determine the diversification benefits investors might derive. We also study the direction of causality in the long run and short run.

The paper is organized as follows. Section 2 reviews the literature on causal relationships between international financial markets. Section 3 describes the data, methodology and hypotheses employed. Section 4 presents the study's results and Section 5 summarizes our conclusions. 


\section{Literature Review}

The literature on the causal relationship between different stock markets looks at groups of countries at a global or regional level or at a single country relative to other countries. Dheeriya (1993), for example, uses Geweke's (1982) causality test to study the interdependence of 17 stock market indices. The study finds that the UK and US markets have the most influence over other markets relative to key markets such as Japan, France and Canada. Most markets, however, react to movements past or present - in other markets. Examining the periods before and after the 1987 crash, Dheeriya finds a structural shift in the interrelationship between international stock markets.

Richards (1995) examines long-term returns to establish the degree of cointegration among different markets. Using a simulation method, he finds that the strong cointegrated relationship observed in earlier studies is the result of "a failure to adjust asymptotic critical values to take account of the small degrees of freedom that remain" when using the Johansen multivariate estimation method. The alternative cointegration tests he presents confirm that the null hypothesis of no cointegration is generally not rejected. Based on a sample of 16 stock markets, the study concludes that stock market indices have a common world component as well as a permanent and transitory country-specific component.

Meriç et al. (2012) determine the linkages among international stock markets following the 2008 market crash. The study's Granger causality results show that the US stock market has considerable influence over other stock markets in Europe and Asia. Using principal component analysis to group stock markets by their co-movements, the authors show that global investors can use high factor loadings in different principal components to maximize portfolio diversification. Their time-varying correlation analysis shows that the benefits of international diversification have decreased since 2008, given the growing correlation among international stock markets.

At the regional level, Huang, Yang and $\mathrm{Hu}$ (2000) examine cointegration and causality among stock markets in the US, Japan and the South China Growth Triangle. ${ }^{1}$ Using advanced unit root and cointegration techniques that allow for structural breaks, they find no

\footnotetext{
${ }^{1}$ Huang et al., who define this area as Hong Kong, Taiwan and the southern part of the People's Republic of China, argue that a common culture (Confucianism) and language should help create an integrated capital market.
} 
evidence of cointegration among these stock markets, except for the Shenzhen and Shanghai indices. The study shows that price changes in the US can be used to predict next-day price changes in Taiwan and Hong Kong. The returns earned on the Hong Kong and US stock markets are contemporaneous and there is significant feedback between the Shenzhen and Shanghai stock exchanges.

Tabak and Lima (2003) assess cointegration and causality among the US market and a sample of Latin and Central American stock markets (Argentina, Brazil, Chile, Colombia, Mexico, Peru and Venezuela). They find evidence of short-term causality, but none of cointegration. The results establish Granger causality between the Brazilian stock market and the other Latin American stock markets. Using impulse response functions, the authors find that the DIJA has a heterogeneous effect on the other stock markets. The US stock market has the greatest influence over the Mexican stock market, given that the two are highly integrated.

Beine, Capelle-Blancard and Raymond (2008) study the linear and nonlinear relationships among stock markets in the US and four other countries: France, Germany, Japan and the UK. They establish a directional linear dependence from the US to the rest of the sample and a strong contemporaneous linear dependence among the latter. The study shows that, consistent with the financial liberalization of the 1980s and 1990s, causality increased after 1987. The results indicate bidirectional nonlinear causality among the daily returns of these stock markets. The authors filter out heteroskedasticity using a FIGARCH model to test for spurious causality. There is a large fall in the number of significant nonlinear causality lags, which points to heteroskedasticity in previous findings. When structural breaks are controlled for, the linear causality remains, while numerous nonlinear relationships disappear.

Among studies that look at the effect of various stock markets on a single stock market, Panda and Acharya (2011) study the integration of the Indian stock market with the US stock market and key Asian stock markets between 2001 and 2008 - a period during which the Indian stock market was affected by foreign institutional investors continuously moving funds across global markets. Employing Granger causality, vector autoregression (VAR), Johansen-Juselius cointegration and innovation accounting analysis, the study looks at the long-term and short-term dynamic relationships among the sample. It finds that the Indian stock market has a cointegrated relationship with the US stock market. A similar relationship emerges with Hong Kong pre-crisis and with China post-crisis, but there is no significant relationship with the other Asian countries. 
Hatemi (2012) analyzes the cointegration between the UAE and US stock markets using symmetric and asymmetric Granger causality. The standard symmetric causality tests show that the UAE market is segmented from the US market. However, the asymmetric causality tests, which separate the causal impact of negative shocks from positive ones, reveal that the UAE market is integrated with the US stock market. The study also finds that the degree of integration is higher when stock markets are falling rather than rising.

Dasgupta (2014) studies the integration of the BRIC stock markets (Brazil, Russia, India and China), using Johansen-Juselius and EngleGranger cointegration as well as pairwise cointegration tests. The study uses VAR and variance decomposition for a more robust analysis. Its results indicate long-run and short-run bidirectional Granger causality between the Indian and Brazilian stock markets. In addition, movements in the Chinese stock market affect the Brazilian stock market, which in turn affects the Russian stock market. Dasgupta concludes that the BRIC countries are favorable environments for investment and that the Indian stock market tends to dominate its BRIC counterparts.

Rehman and Hazazi (2014) focus on the Saudi stock market and its relationship with stock markets in the Gulf Cooperation Council countries, Japan, the UK and the US. Using Pearson correlation, the unit root test, Johansen cointegration and pairwise causality tests, the study points to growing correlation among these markets over time and a fall in the volatility of the Saudi index (TASI), although there is no evidence that any one stock market drives the others.

Overall, the literature shows that causal relationships exist among international markets, irrespective of geographical proximity. Movements in certain stock markets clearly affect others, but this does not preclude opportunities for diversification internationally. Drawing on this, we assess the causal relationships and potential for diversification in a sample of nine stock markets in Asia with respect to the US stock market.

\section{Data and Methodology}

The daily time-series data for the nine Asian stock markets and the US stock market was obtained from the Bloomberg, Investing.com and Yahoo Finance databases. ${ }^{2}$ The study's sample period is 2 January

2 Available from https://www.bloomberg.com/asia, https://www.investing.com/ and https://finance.yahoo.com/, respectively. We have selected a combination of developed and developing Asian markets to ensure that the sample is representative of the region. 
1991 to 31 March 2016 for all selected stock markets, barring the Hanoi Stock Exchange, which did not become operational until 18 May 2005. In this case, we use the period 18 May 2005 to 31 March 2016.

Given the nature of the analysis, the data is prone to heteroskedasticity. One method of controlling for this is to weight each observation by the inverse of the standard deviation of the error. This is an effective method in a least squares regression analysis once we identify the existence and scale of heteroskedasticity. If it comprises a small number of unidentified parameters, we can measure the variance of every residual and apply the weights to correct the heteroskedasticity. However, if the nature of the heteroskedasticity cannot be determined, an alternative is to use heteroskedasticity-consistent covariance matrices. In nonlinear models, where the nature of heteroskedasticity may be hard to identify, we cannot establish an appropriate variance-stabilizing transformation and assess weights in a least squares analysis (see Long \& Ervin, 2000; Greene, 1997). Since the time-series data is skewed and the variances are not constant, we convert the daily time-series data for the ten stock price indices into natural logarithm form to resolve the heteroskedasticity problem (Bhunia, 2012). The sample indices and their corresponding variables are listed below.

\begin{tabular}{llc}
\hline Country & \multicolumn{1}{c}{ Index name } & Variable \\
\hline India & BSE Sensex & $l s x$ \\
China & Shanghai Stock Exchange (SSE) Composite Index & $l s c i$ \\
Japan & Nikkei & $l n k$ \\
Korea & Korea Composite Stock Price Index (KOSPI) & $l k p i$ \\
Vietnam & Hanoi Stock Exchange Equity Index (HNX Index) & $l h n x$ \\
Indonesia & Jakarta Stock Exchange Composite Index (JCI) & $l j c i$ \\
Malaysia & FBM Kuala Lumpur Composite Index (KLCI) & $l k c i$ \\
Philippines & Philippine Stock Exchange Composite Index (PSEi) & $l p c i$ \\
Singapore & FTSE Straits Times Index (STI) & $l s t i$ \\
US & Dow Jones Industrial Average (DJIA) & $l d j i$ \\
\hline
\end{tabular}

\section{Empirical Results and Analysis}

This section provides the descriptive statistics for the sample and carries out a correlation analysis, unit root test and Johansen cointegration analysis. It also generates a vector error correction model (VECM) and carries out robustness checks. 


\subsection{Descriptive Statistics}

We start by testing the distribution of the sample. Our null hypothesis is that the stock price indices are distributed normally. This is consistent with Fama (1965) and Aparicio and Estrada (1997) who argue that stock market prices are distributed normally if the indices follow the random walk theory.

Table 1 shows that the Japanese stock market has the highest average (natural logarithm) price (9.57) of the ten stock markets, while the Indonesian stock market has the lowest (3.90), consistent with Lingaraja, Selvam and Vasanth (2015). The median prices follow a similar pattern to the average prices. The Indonesian stock market has the highest average daily stock returns (0.036 percent), while the Thai stock market has the lowest average daily returns ( -0.034 percent; not tabulated).

The Indian stock market has the highest standard deviation (0.84) followed by the Chinese stock market (0.71), which indicates that prices in the former are more variable than those in the other stock markets. The kurtosis is greater than the skewness (for which seven out of ten results are negative) across the entire sample, which shows that the distribution is platykurtic. The Jarque-Bera statistics also confirm that the series is not normally distributed. Therefore, the null hypothesis is rejected statistically, which means that the stock prices indices in this sample do not represent a normal distribution.

Table 1: Descriptive statistics

\begin{tabular}{lcccccccccc}
\hline & ldji & lhnx & ljci & lkci & lkpi & lnk & lpci & lsci & lsti & lsx \\
\hline Mean & 9.06 & 4.72 & 3.90 & 6.95 & 6.89 & 9.57 & 7.81 & 7.28 & 7.69 & 8.85 \\
Median & 9.24 & 4.52 & 3.92 & 6.93 & 6.82 & 9.64 & 7.78 & 7.36 & 7.68 & 8.55 \\
Max. & 9.81 & 6.13 & 4.84 & 7.54 & 7.71 & 10.21 & 9.00 & 8.71 & 8.26 & 10.30 \\
Min. & 7.81 & 3.93 & 2.16 & 5.57 & 5.63 & 8.86 & 6.37 & 4.66 & 6.69 & 6.86 \\
SD & 0.51 & 0.53 & 0.41 & 0.35 & 0.56 & 0.30 & 0.57 & 0.71 & 0.31 & 0.84 \\
Skewness & -0.82 & 0.71 & -0.47 & -0.27 & -0.21 & -0.25 & 0.32 & -1.18 & -0.28 & 0.14 \\
Kurtosis & 2.57 & 2.52 & 3.44 & 2.77 & 1.96 & 1.95 & 2.29 & 5.19 & 2.29 & 1.69 \\
JB stat. & 748.6 & 243.8 & 282.1 & 85.2 & 324.7 & 350.1 & 232.4 & $2,794.5$ & 218.9 & 455.7 \\
Obs. & 6,280 & 2,582 & 6,361 & 6,023 & 6,221 & 6,221 & 6,208 & 6,440 & 6,346 & 6,067 \\
\hline
\end{tabular}

Note: Sample indices denoted by: lsx = Sensex, lsci = SSE Composite Index, lnk = Nikkei, lkpi = KOSPI, lhnx = HNX Index, ljci = JCI, lkci = KLCI, lpci = PSEi, lsti = STI, ldji = DJIA. $\mathrm{JB}=$ Jarque-Bera test, $\mathrm{SD}=$ standard deviation.

Source: Authors' calculations based on data from Bloomberg, Investing.com and Yahoo Finance. 
Secondary stochastic theory is a different justification for the fat tail of the observed allocation of stock price indices. This hypothesis holds that stock price indices are sampled from a range of allotments with diverse, restricted variances. The heteroskedasticity linked with this combination of normal distributions will lead to large kurtosis values in the sample. Consequently, the distribution of fundamental factors is nonstationary over time (see Herve, Chanmalai \& Shen, 2011).

\subsection{Correlation Analysis}

The efficient markets hypothesis is linked to the random walk model, which suggests that, if the information flow is unrestricted, then any new information should be reflected instantly in the stock prices. Since there are numerous common economic factors that affect international stock prices to the extent that these markets are efficient and follow a random walk model, the prices of the sample stock indices should be highly correlated (see Malkiel, 2003). Thus, we hypothesize that the Asian stock markets are positively correlated with the US stock market.

Table 2 gives the correlation coefficients of the stock index prices in our sample. The table shows that the US stock market is negatively correlated with the Vietnamese stock market, but positively correlated with all the other Asian stock markets over the sample period. Interestingly, the Vietnamese stock market is negatively associated with the Indian, Philippine, Korean and Malaysian stock markets as well. These correlation coefficients are statistically significant at the 5 percent level. There is no correlation between the Vietnamese and Singapore stock markets. Four stock markets - the Korean, Malaysian, Singapore and Indian stock markets - show evidence of significant co-movements with the US stock market over the study period. These findings support the hypothesis that the US and Asian markets are highly integrated with each other. 
Table 2: Correlation analysis of stock index prices

\begin{tabular}{lcccccccccc}
\hline & ldji & lhnx & ljci & lkci & lkpi & lnk & lpci & lsci & lsti & lsx \\
\hline ldji & 1.00 & & & & & & & & & \\
lhnx & -0.34 & 1.00 & & & & & & & & \\
ljci & 0.44 & 0.34 & 1.00 & & & & & & & \\
lkci & $0.80^{*}$ & $-0.53^{*}$ & 0.01 & 1.00 & & & & & & \\
lkpi & $0.72^{*}$ & $-0.44^{*}$ & 0.04 & $0.92^{*}$ & 1.00 & & & & & \\
lnk & 0.67 & 0.25 & $0.72^{*}$ & 0.19 & 0.15 & 1.00 & & & & \\
lpci & $0.87^{*}$ & $-0.61^{*}$ & 0.03 & $0.95^{*}$ & $0.83^{*}$ & 0.30 & 1.00 & & & \\
lsci & 0.21 & 0.33 & -0.11 & 0.33 & 0.43 & 0.17 & 0.25 & 1.00 & & \\
lsti & $0.68^{*}$ & 0.00 & 0.50 & 0.68 & 0.71 & 0.39 & 0.58 & 0.39 & 1.00 & \\
lsx & $0.78^{*}$ & $-0.39^{*}$ & $-0.01^{*}$ & $0.91^{*}$ & $0.85^{*}$ & 0.31 & $0.89^{*}$ & 0.47 & 0.60 & 1.00 \\
\hline
\end{tabular}

Note: Sample indices denoted by: lsx = Sensex, lsci = SSE Composite Index, lnk = Nikkei, lkpi = KOSPI, lhnx = HNX Index, ljci = JCI, lkci = KLCI, lpci = PSEi, lsti = STI, ldji = DJIA.

* Significant at 5 percent level.

Source: Authors' calculations based on data from Bloomberg, Investing.com and Yahoo Finance.

We use a pairwise correlation analysis to test the linear statistical interdependence between the US and Asian stock markets, but this does not confirm the existence of any stable long-run association. Instead, we use cointegration analysis to demonstrate this association, which gauges the correlation between two nonstationary variables in a stationary way.

\subsection{Unit Root Test Analysis}

A regression analysis using time-series data requires stationary data to produce meaningful results. In the case of nonstationary data, the Johansen cointegration test is used to determine the relationship between variables. A condition for cointegration among the sample stock markets is that their data should be nonstationary and integrated of an order higher than 0 . We test stationarity using the augmented Dickey-Fuller (ADF) and Phillips-Perron (PP) unit root tests before proceeding to the cointegration test.

Both the unit root and cointegration tests for pertinent financial indicators help establish time-series attributes. These tests are significant because they demonstrate the number of times a variable must be differenced to yield a stationary value. Financial indicators that are stationary are described as $\mathrm{I}(0)$, while those that need to be first-differenced are termed I(1). The ADF and PP tests determine the existence of a unit root. We test the null hypothesis that all the selected stock markets have a unit root against the alternative hypothesis of no unit root. 
Table 3 gives the results of the unit root tests, indicating that none of the stock index prices in the sample are originally stationary, but that all of them become stationary when first-differenced. Thus, the null hypothesis is accepted because the stock price indices are not stationary at level. Since the time-series data is nonstationary at level, regular regression would generate spurious results. Accordingly, we use the Johansen cointegration test to determine the existence of long-run associations in the sample.

Table 3: Unit root test results

\begin{tabular}{lcccc}
\hline & \multicolumn{2}{c}{ At level } & \multicolumn{2}{c}{ First-differenced } \\
\cline { 2 - 5 } Variable & ADF t-stat & PP t-stat & ADF t-stat & PP t-stat \\
\hline ldji & 0.64 & 0.40 & -14.95 & -84.03 \\
lhnx & -1.38 & -1.42 & -18.70 & -44.54 \\
ljci & -2.35 & -2.32 & -57.60 & -79.44 \\
lkci & -2.02 & -1.92 & -11.62 & -74.35 \\
lkpi & -1.71 & -1.63 & -12.87 & -73.06 \\
lnk & -1.50 & -1.54 & -58.37 & -81.83 \\
lpci & -0.86 & -0.72 & -19.07 & -66.47 \\
lsci & 0.04 & 0.30 & -14.42 & -77.52 \\
lsti & -1.46 & -1.29 & -20.01 & -73.47 \\
lsx & 0.03 & 0.04 & -16.73 & -70.88 \\
\hline
\end{tabular}

Note: Sample indices denoted by: lsx = Sensex, lsci = SSE Composite Index, lnk = Nikkei, lkpi = KOSPI, lhnx = HNX Index, ljci = JCI, lkci = KLCI, lpci = PSEi, lsti = STI, ldji = DJIA.

* Significant at 5 percent level. Coefficient of variation at 5 percent is -2.86 , indicating that the decision is not stationary at level and stationary when first-differenced.

Source: Authors' calculations based on data from Bloomberg, Investing.com and Yahoo Finance.

\subsection{Johansen Cointegration Analysis}

Financial theory holds that economic variables should be integrated or follow a random walk. Cointegration tests help identify any significant association between variables. Variables with diverse trends cannot have a long-run association with each other, suggesting that there is generally no support for deductions based on model allocations (Sjö, 2008). In general, we presume that the system is integrated of order I(1), the idea being that international stock markets are likely to be cointegrated under the Johansen cointegration test assumption (Yusupov \& Duan, 2010) since many of the same variables affect market performance, resulting in cointegration in the long run. 
Before performing the test, we need to determine the optimal lag length for the sample. This applies to the Johansen cointegration test as well as the vector error correction and causality tests. The criteria used here are the Akaike information criterion (AIC), the Schwarz Bayesian criterion (SBC) and the Hannan-Quinn criterion (HQC). Keeping in mind that a smaller lag length implies a better model, we choose a maximum lag order of 2. Table A1 in the Appendix shows that the SBC and HQC yield a lag order of 1 and the AIC a lag order of 2. Ivanov and Kilian (2001) argue that the SBC and HQC provide better results for quarterly models, whereas the AIC should be used in models spanning a shorter period. Since we are using daily data, we select an optimal lag length of 2 (the AIC yields a minimum value of -55.34 overall).

Johansen cointegration is a standard method of determining longrun relationships in time-series data in a VECM. Having established that the prices of the stock market indices in our sample become stationary when first-differenced and selected a lag length of 2, we use a critical value of 5 percent in the Johansen cointegration test (Osterwald-Lenum, 1992). Additionally, we employ a complementary deduction procedure involving deterministic factors on the condition that the linear trend is assumed to be fundamentally linear and not quadratic (Lütkepohl \& Saikkonen, 2000).

The cointegration test results are given in Table 4, which measures two likelihood ratios: the maximum eigenvalues and trace statistics. The latter exceed their critical value ( $r \leq 0$ and $r \leq 4)$, with five cointegrating equations. The maximum eigenvalue statistics exceed their critical value $(r \leq 0$ and $r \leq 4)$, with five cointegrating equations, which is significant at the 5 percent level. Therefore, both test results confirm the long-run association among the selected variables, consistent with Bhunia (2013) and Hussin et al. (2013). The long-run relationship among the ten stock market indices is illustrated in Figure 1. 


\section{Table 4: Johansen cointegration test results}

Unrestricted cointegration rank test (trace)

\begin{tabular}{lcccc}
\hline $\begin{array}{l}\text { Hypothesized } \\
\text { number of CE(s) }\end{array}$ & Eigenvalue & Trace statistic & $\begin{array}{c}\mathbf{0 . 0 5} \text { critical } \\
\text { value }\end{array}$ & Probability \\
\hline $\mathrm{r} \leq 0^{*}$ & 0.04 & 461.80 & 239.23 & 0.00 \\
$\mathrm{r} \leq 1^{*}$ & 0.03 & 341.23 & 197.37 & 0.00 \\
$\mathrm{r} \leq 2^{*}$ & 0.02 & 247.31 & 159.52 & 0.00 \\
$\mathrm{r} \leq 3^{*}$ & 0.02 & 173.83 & 125.61 & 0.00 \\
$\mathrm{r} \leq 4^{*}$ & 0.01 & 103.87 & 95.75 & 0.01 \\
$\mathrm{r} \leq 5$ & 0.01 & 68.92 & 69.81 & 0.05 \\
$\mathrm{r} \leq 6$ & 0.01 & 46.46 & 47.85 & 0.06 \\
$\mathrm{r} \leq 7$ & 0.01 & 26.24 & 29.79 & 0.12 \\
$\mathrm{r} \leq 8$ & 0.00 & 13.24 & 15.49 & 0.10 \\
$\mathrm{r} \leq 9$ & 0.00 & 3.49 & 3.84 & 0.06 \\
\hline
\end{tabular}

Unrestricted cointegration rank test (maximum eigenvalue)

\begin{tabular}{lcccc}
\hline $\begin{array}{l}\text { Hypothesized } \\
\text { number of CE(s) }\end{array}$ & Eigenvalue & $\begin{array}{c}\text { Max eigen } \\
\text { statistic }\end{array}$ & $\begin{array}{c}\mathbf{0 . 0 5} \text { critical } \\
\text { value }\end{array}$ & Probability \\
\hline $\mathrm{r} \leq 0^{*}$ & 0.04 & 120.57 & 64.50 & 0.00 \\
$\mathrm{r} \leq 1^{*}$ & 0.03 & 93.92 & 58.43 & 0.00 \\
$\mathrm{r} \leq 2^{*}$ & 0.02 & 73.47 & 52.36 & 0.00 \\
$\mathrm{r} \leq 3^{*}$ & 0.02 & 69.95 & 46.23 & 0.00 \\
$\mathrm{r} \leq 4^{*}$ & 0.01 & 44.94 & 40.07 & 0.01 \\
$\mathrm{r} \leq 5$ & 0.01 & 22.45 & 33.87 & 0.57 \\
$\mathrm{r} \leq 6$ & 0.01 & 20.22 & 27.58 & 0.32 \\
$\mathrm{r} \leq 7$ & 0.01 & 13.00 & 21.13 & 0.45 \\
$\mathrm{r} \leq 8$ & 0.00 & 8.74 & 14.26 & 0.30 \\
$\mathrm{r} \leq 9$ & 0.00 & 3.49 & 3.84 & 0.06 \\
\hline
\end{tabular}

Note: * Rejection of hypothesis at 5 percent level. Probability = MacKinnon-Haug-Michelis p-values. Max eigenvalue test indicates cointegrating equations at 5 percent level.

Source: Authors' calculations based on data from Bloomberg, Investing.com and Yahoo Finance.

Figure 1: Cointegration among stock market indices

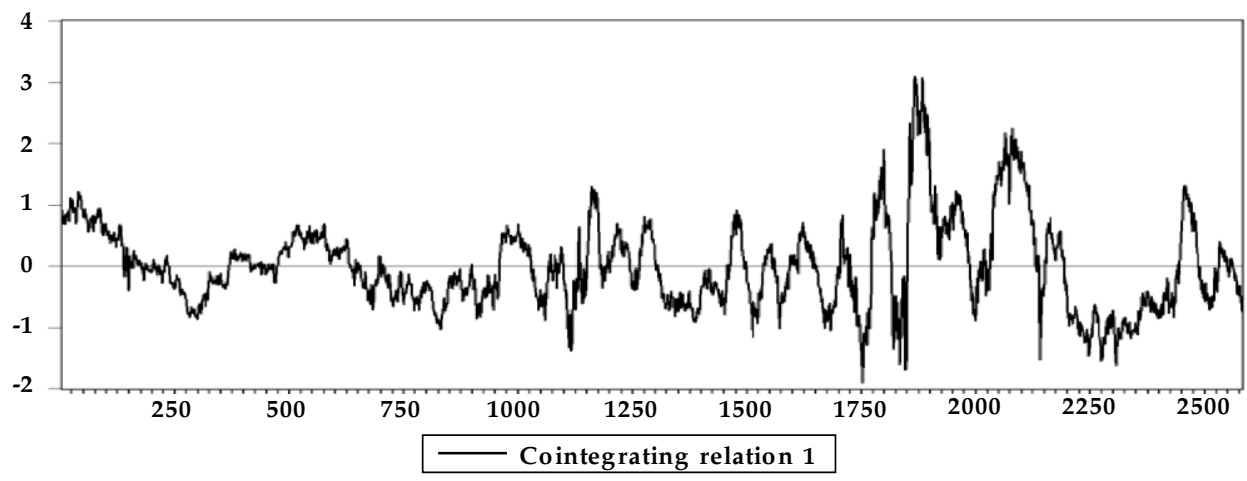

Source: Authors' calculations based on data from Bloomberg, Investing.com and Yahoo Finance. 


\subsection{Vector Error Correction Analysis}

Since the stock price indices in the sample have more than one cointegrating vector, we use a VECM that adjusts to short-term transformations in variables as well as divergences from stability. The cointegration rank confirms the number of cointegrating vectors. For example, a rank of 5 indicates that those five linearly independent combinations of nonstationary variables will be stationary. A negative coefficient in the error correction model indicates that any short-run variations between the exogenous and endogenous variables will lead to a steady long-term association among the variables (Asari et al., 2011). Thus, when long-run causality survives, the short-run causality should be tested (Joshi, 2013).

Given that the stock index values are not stationary at level (have to be first-differenced to become stationary) and are cointegrated of the same order, we cannot use an unrestricted VAR model. Thus, we use a restricted VAR model or VECM with an optimal lag length of 2 (see above) and the residuals of the model to test causality (Table 5). To examine the causal relationship between the US stock market and Asian stock markets in the short run and long run, we use the average stock prices of the nine Asian stock markets. The results confirm that there is a long-term relationship between the US and Asian stock markets. The natural logarithm of the price of the DIJA (ldji) and the natural logarithm of the average price of the Asian stock markets (lasma) are used as dependent as well as independent variables. We estimate the VECM as follows:

$$
\begin{aligned}
& D(\text { ldji })=-0.01(\text { ldji }(-1)+2.25 \text { lasma }(-1)-25.29)-0.05 D(\text { ldji }(-1))-0.04 \\
& D(\text { ldji }(-2))+0.01 D(\text { lasma }(-1))+0.01 D(\text { lasma }(-2))-0.0003 \\
& D(\text { lasma })=-0.02(\text { ldji }(-1)+2.25 \text { lasma }(-1)-25.29)-0.01 D(\text { ldji }(-1))-0.01 \\
& D(\text { ldji }(-2))+0.02 D(\text { lasma }(-1))-0.004 D(\text { lasma }(-2))-0.0003
\end{aligned}
$$

In Table 5, $C(1)$ and $C(7)$ are the coefficients of the cointegrating model and error correction term, which demonstrates the speed of adjustment toward equilibrium. This variable is the residual of the oneperiod lag of the cointegrating vector of the US stock market and selected Asian stock markets. Both $C(1)$ and $C(7)$ are negative $(-0.01$ and -0.02$)$ and statistically significant since the probability is 0 . This indicates a significant degree of long-run causality between the US and Asian stock markets. Both the R2 and adjusted R2 terms are more than 0.60, indicating that the data fits the model well. The probability of the F- 
statistic is 0.00 , which implies that the Asian stock market indices (asma) have a significant effect on the DIJA (dji).

Next, we test the short-run association between the Asian stock markets and the US market by estimating the coefficients of the lagged difference terms and using the Wald test to determine the existence of shortrun causality. Table 6 indicates that the probability of the Wald test statistic is lower than 0.05 in both cases, implying that there is significant short-term causality in both directions (to and from the Asian and US stock markets).

Table 5: VECM test results

\begin{tabular}{lcc}
\hline Error correction & D (ldji) & D (lasma) \\
\hline CointEq1 & -0.01 & -0.02 \\
& {$[0.60]$} & {$[3.29]$} \\
& $(0.00)$ & $(0.00)$ \\
D (ldji (-1)) & -0.05 & -0.01 \\
& {$[-4.57]$} & {$[-0.42]$} \\
& $(0.00)$ & $(0.00)$ \\
D (ldji (-2)) & -0.04 & -0.01 \\
& {$[-3.29]$} & {$[-1.02]$} \\
& $(0.00)$ & $(0.03)$ \\
D (lasma (-1)) & 0.01 & 0.02 \\
& {$[1.86]$} & {$[1.85]$} \\
& $(0.04)$ & $(0.03)$ \\
D (lasma (-2)) & 0.00 & -0.00 \\
& {$[0.40]$} & {$[-0.32]$} \\
C & $(0.04)$ & $(0.02)$ \\
Probability & -0.00 & -0.00 \\
Adjusted R & {$[-2.38]$} & {$[-1.83]$} \\
& $(0.01)$ & $(0.05)$ \\
& 0.61 & 0.67 \\
& 0.59 & 0.63 \\
& 5.97 & 4.11 \\
& 0.00 & 0.00 \\
\hline
\end{tabular}

Note: Sample indices denoted by: lasma $=$ selected Asian stock market indices, $l$ dji $=$ DJIA. $\mathrm{t}$-statistics given in brackets and probabilities in parentheses.

Source: Authors' calculations based on data from Bloomberg, Investing.com and Yahoo Finance. 
Table 6: Short-run causality (Wald test) results

\begin{tabular}{lccc}
\hline Test statistic & Value & df & Probability \\
\hline Chi-square & Equation: ldji and lasma & 2 & 0.00 \\
& 21.23 & 2 & 0.00 \\
Chi-square & Equation: lasma and ldji & & \\
\hline
\end{tabular}

Note: Sample indices denoted by: lasma $=$ selected Asian stock market indices, $l$ dji $=$ DJIA. Source: Authors' calculations based on data from Bloomberg, Investing.com and Yahoo Finance.

\subsection{Robustness Checks}

For the VECM and Wald model above to fit the data, the following conditions must hold: (i) there should be no serial correlation in the residuals, (ii) the residuals should be homoskedastic and normally distributed, and (iii) the model should be stable. The Breusch-Godfrey LM, Breusch-Pagan-Godfrey and Jarque-Bera tests determine serial correlation, heteroskedasticity and distribution, respectively, and we generate a cumulative sum control chart (CUSUM) to gauge stability. Table 7 and Figure 2 give the results of the residual tests.

Table 7: Robustness test results

\begin{tabular}{|c|c|c|c|}
\hline Test & Value & Probability & Value \\
\hline \multicolumn{4}{|c|}{ Serial correlation } \\
\hline \multicolumn{4}{|c|}{ Breusch-Godfrey LM } \\
\hline F-statistic & 2.92 & Prob. F $(22,556)$ & 0.053 \\
\hline Obs. ${ }^{*} \mathrm{R}^{2}$ & 5.89 & Prob. chi-square (2) & 0.052 \\
\hline \multicolumn{4}{|c|}{ Heteroskedasticity } \\
\hline \multicolumn{4}{|c|}{ Breusch-Pagan-Godfrey } \\
\hline F-statistic & 122.43 & Prob. F $(302,549)$ & 0.056 \\
\hline Obs. ${ }^{*} \mathrm{R}^{2}$ & 938.97 & Prob. chi-square (30) & 0.054 \\
\hline \multicolumn{4}{|l|}{ Normality } \\
\hline \multicolumn{4}{|c|}{ Jarque-Bera } \\
\hline JB statistic & 499.23 & Probability & 0.065 \\
\hline
\end{tabular}

Source: Authors' calculations based on data from Bloomberg, Investing.com and Yahoo Finance.

The Breusch-Godfrey serial correlation LM test statistic shows that there is no serial correlation because the probability of the observed R-squared term (0.052) is greater than 0.05. The Breusch-Pagan-Godfrey 
heteroskedasticity test result indicates the absence of heteroskedasticity as the probability of the observed R-squared term (0.054) is greater than 0.05 . The Jarque-Bera statistic is greater than 0.05 , which indicates that the residuals are normally distributed. Finally, the CUSUM test results indicate that the model is stable as the data falls within the 5 percent significance level (Figure 2).

Figure 2: CUSUM test results for model stability

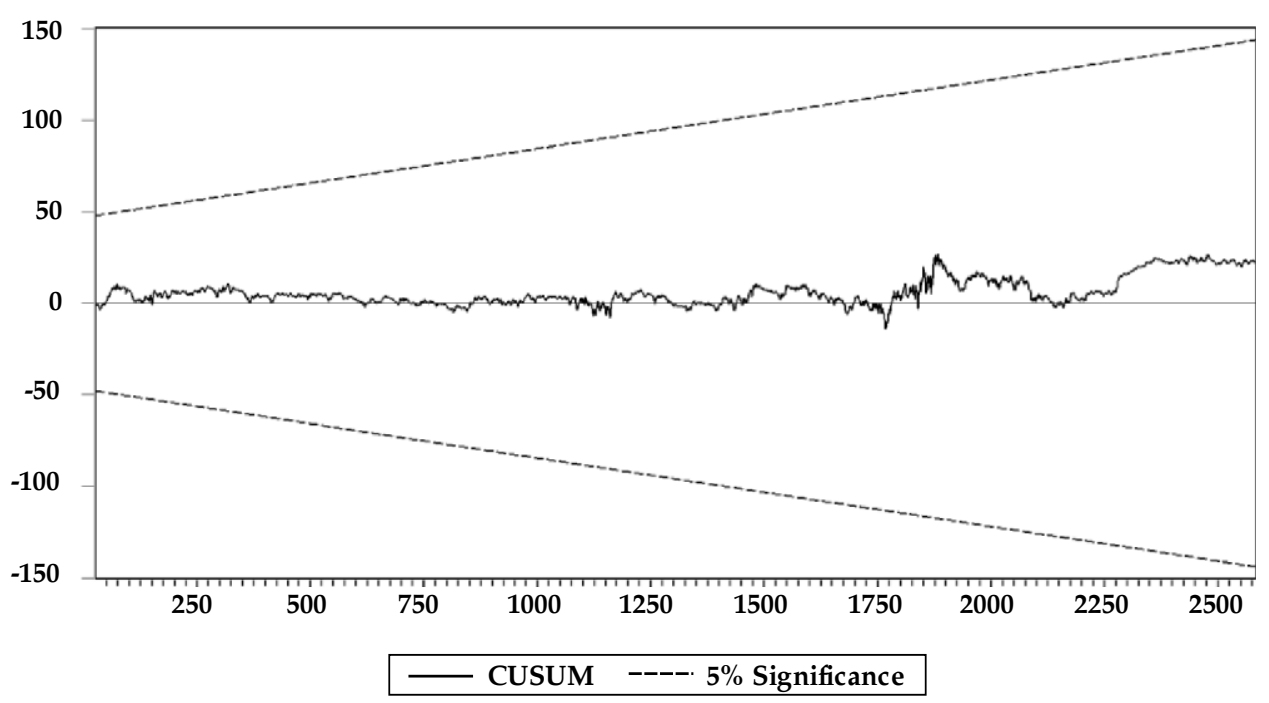

Source: Authors' calculations based on data from Bloomberg, Investing.com and Yahoo Finance.

\section{Conclusion}

This study examines the causal relationship between nine Asian stock markets and the US financial market. We find a positive association between the latter and most of the Asian stock markets in our sample. An exception is the Vietnamese stock market, which has a negative correlation with the US financial market, indicating opportunities for diversification by investors.

The time series stock index values are not stationary at level but stationary at first difference. The Johansen cointegration test results indicate that all the stock markets have a long-run association of the same order. The VECM test results confirm that there is significant long-run as well as shortrun causality in both directions between the US financial market and the rest of the sample. These findings reflect the degree of integration between the US and Asian stock markets, but also point to valuable opportunities for international investors to diversify their portfolios across these markets. 


\section{References}

Aberdeen Asset Management, Henderson Global Investors and What Investment. (2016). Investing in Asia: Turning to the Far East for high returns. London: Authors. Available from http://asia.investmentintelligence.co.uk/

Aparicio, F., \& Estrada, J. (1997). Empirical distributions of stock returns: Scandinavian securities markets, 1990-95. Unpublished manuscript, Carlos III University, Madrid.

Asari, F. F. A. H., Baharuddin, N. S., Jusoh, N., ... Jusoff, K. (2011). A vector error correction model (VECM) approach in explaining the relationship between interest rate and inflation towards exchange rate volatility in Malaysia. World Applied Sciences Journal, 12, 49-56.

Beine, M., Capelle-Blancard, G., \& Raymond, H. (2008). International nonlinear causality between stock markets. European Journal of Finance, 14(8), 663-686.

Bhunia, A. (2012). Association between crude price and stock indices: Empirical evidence from Bombay Stock Exchange. Journal of Economics and Sustainable Development, 3(3), 25-34.

Bhunia, A. (2016, April). Dependence of Indian stock market on major ASEAN stock markets. Paper presented at the International Symposium on Business and Management, Bangkok.

Dasgupta, R. (2014). Integration and dynamic linkages of the Indian stock market with BRIC: An empirical study. Asian Economic and Financial Review, 4(6), 715-731.

Dheeriya, P. L. (1993). Further evidence on causality and feedback across international stocks. Journal of Economics and Finance, 17(3), 160-167.

Fama, E. F. (1965). The behavior of stock-market prices. Journal of Business, 38(1), 34-105.

Forbes, K. J. (2008). Why do foreigners invest in the United States? (Working Paper No. 13908). Cambridge, MA: National Bureau of Economic Research. 
Greene, W. H. (1997). Econometric analysis (3rd ed.). Upper Saddle River, NJ: Prentice Hall.

Hatemi, A. (2012). Is the UAE stock market integrated with the USA stock market? New evidence from asymmetric causality testing. Research in International Business and Finance, 26(2), 273-280.

Herve, D. B. G., Chanmalai, B., \& Shen, Y. (2011). The study of causal relationship between stock market indices and macroeconomic variables in Cote d'Ivoire: Evidence from error-correction models and Granger causality test. International Journal of Business and Management, 6(12), 146-169.

Huang, B.-N., Yang, C.-W., \& Hu, J. W.-S. (2000). Causality and cointegration of stock markets among the United States, Japan and the South China Growth Triangle. International Review of Financial Analysis, 9(3), 281-297.

Hussin, M. Y. M, Muhammad, F., Razak, A. A., Tha, G. P., \& Marwan, N. (2013). The link between gold price, oil price and Islamic stock market: Experience from Malaysia. Journal of Studies in Social Sciences, 4(2), 161-182.

Ivanov, V., \& Kilian, L. (2001). A practitioner's guide to lag-order selection for vector autoregressions (Discussion Paper No. 2685). London: Centre for Economic Policy Research.

Joshi, A. (2013). Long-term causality of GDP-led export (GLE) using VECM model with reference to India. Prestige International Journal of Management and IT, 2(1), 15-25.

Lingaraja, K., Selvam, M., \& Vasanth, V. (2015). Long-run dynamic linkages between emerging stock markets in Asia and a developed stock market (DJIA). Research Journal of Applied Sciences, 10(5), 203-211.

Long, J. S., \& Ervin, L. H. (2000). Using heteroscedasticity-consistent standard errors in the linear regression model. American Statistician, 54(3), 217-224. 
Lütkepohl, H., \& Saikkonen, P. (2000). Testing for the cointegrating rank of a VAR process with a time trend. Journal of Econometrics, 95(1), 177-198.

Malkiel, B. G. (2003). The efficient market hypothesis and its critics. Journal of Economic Perspectives, 17(1), 59-82.

Meriç, G., Lentz, C., Schmeltz, W., \& Meriç, I. (2012). International evidence on market linkages after the 2008 stock market crash. International Journal of Business and Finance Research, 6(4), 45-57.

Osterwald-Lenum, M. (1992). A note with quantiles of the asymptotic distribution of the maximum likelihood cointegration rank test statistics. Oxford Bulletin of Economics and Statistics, 54(3), 461-472.

Panda, P. K., \& Acharya, D. (2011). Stock market integration: Evidence from India and other major world stock markets. Indian Journal of Economics and Business, 10(4), 605-628.

Rehman, M. Z., \& Hazazi, M. A. (2014). Examining linkages between Saudi stock market (TASI) and selected stock market indices. International Journal of Financial Research, 5(4), 196-209.

Richards, A. J. (1995). Co-movements in national stock market returns: Evidence of predictability, but not cointegration. Journal of Monetary Economics, 36(3), 631-654.

Sjö, B. (2008). Testing for unit roots and cointegration. Unpublished manuscript, Linköping University, Sweden. Retrieved from https://pdfs.semanticscholar.org/7ce6/2a0c7f6dab85f264a5403bf 9b99a0f20a156.pdf

Tabak, B. M., \& Lima, E. J. A. (2003). Causality and cointegration in stock markets: The case of Latin America. Brazilian Journal of Business Economics, 3(2), 27-45.

Thorpe, D. (2016). Investing in Asia. Aberdeen Henderson Global Investors Bulletin.

Yusupov, G., \& Duan, W. (2010). Long-run relationships between base metals, gold and oil. Unpublished Master's thesis, Lund University, School of Economics and Management, Lund, Sweden. 


\section{Appendix}

Table A1 gives the optimal variable lag selection for the stock market indices in our sample, which comprises nine Asian stock markets and the US stock market. In each case, we take the natural logarithm of the daily price of that index, employing the AIC, SBC and HQC to determine the optimal lag.

Table A1: Optimal lag selection

\begin{tabular}{lclllll}
\hline Lag & LogL & \multicolumn{1}{c}{ LR } & \multicolumn{1}{c}{ FPE } & AIC & \multicolumn{1}{c}{ SBC } & HQC \\
\hline 0 & $14,893.13$ & NA & $4.62 \mathrm{e}-18$ & -11.53 & -11.51 & -11.52 \\
1 & $71,434.24$ & $112,600.1$ & $4.60 \mathrm{e}-37$ & -55.29 & $-55.04^{*}$ & $-55.19^{*}$ \\
2 & $71,610.85$ & $350.34^{*}$ & $4.34 \mathrm{e}-37^{*}$ & $-55.34^{*}$ & -54.87 & -55.17 \\
\hline
\end{tabular}

Note: ${ }^{*}$ Lag order selected based on the criterion LR test statistic, with each test at the 5 percent level.

Source: Authors' calculations based on data from Bloomberg, Investing.com and Yahoo Finance. 